\title{
Molecular Cloning and Phylogenetic Analysis of a Chitin Deacetylase Isolated from the Epidermis of the Red Snow Crab Chionoecetes japonicus
}

\author{
Kakeru Fujimori, Hideto Fukushima, Masahiro Matsumiya \\ Department of Marine Science and Resources, College of Bioresource Sciences, Nihon University, Fujisawa, Japan \\ Email:matsumiya@brs.nihon-u.ac.jp
}

How to cite this paper: Fujimori, K. Fukushima, H. and Matsumiya, M. (2018) Molecular Cloning and Phylogenetic Analysis of a Chitin Deacetylase Isolated from the Epidermis of the Red Snow Crab Chionoecetes japonicus. Advances in Bioscience and Biotechnology, 9, 52-62. https://doi.org/10.4236/abb.2018.91005

Received: December 26, 2017

Accepted: January 27, 2018

Published: January 30, 2018

Copyright $\odot 2018$ by authors and Scientific Research Publishing Inc. This work is licensed under the Creative Commons Attribution International License (CC BY 4.0).

http://creativecommons.org/licenses/by/4.0/

(c) (i) Open Access

\begin{abstract}
Chitin deacetylase (CDA; EC 3. 5. 1. 41) catalyzes the deacetylation of chitin. In this study, we successfully cloned and sequenced a chitin deacetylase gene from the red snow crab Chionoecetes japonicus. By using reverse transcription-polymerase chain reaction (RT-PCR) and 5 ' and 3 'rapid amplification of cDNA ends, we obtained a 2141-bp amplicon containing a chitin deacetylase gene $(C j C D A)$ from the epidermis of $C$. japonicus. The amplicon contains a 1575 -bp open reading frame that is predicted to encode a 525-amino acid protein. The structure predicted from the deduced amino acid sequence included an N-terminal signal peptide, chitin-binding domain (CBD), low-density lipoprotein receptor class A domain (LDL-A), and catalytic domain. Comparative analysis of the deduced amino acid sequence of $C j C D A$ revealed the highest homology (74\%) to gastrolith protein 59 of Cherax quadricarinatus. We used RT-PCR to evaluate the expression of $C j C D A$ in various tissues of $C$. japonicus, and we observed that $C j C D A$ was expressed only in the epidermis. A phylogenetic analysis, using the amino acid sequences of CjCDA and other known chitin deacetylases, showed that CjCDA belonged to a group of crustacean chitin deacetylases. To our knowledge, this is the first study reporting the cDNA cloning of a chitin deacetylase from a crab.
\end{abstract}

\section{Keywords}

Chitin Deacetylase, Molecular Cloning, Chionoecetes japonicus, Phylogenetic Analysis, Expression Analysis

\section{Introduction}

Chitin is a $\beta$-1,4-linked linear polysaccharide of $\mathrm{N}$-acetyl-D-glucosamine 
(GlcNAc). Chitin is widespread in nature, and is present in the cell walls of fungi, the exoskeletons of insects and crustaceans, and the cuttlebones of mollusks, and it is the second most abundant component of biomass after cellulose [1]. Chitosan, which is deacetylated chitin [2], is a $\beta$-1,4-linked polymer of glucosamine (GlcN) that is soluble in dilute acids and viscous [3] and is widely used in textile goods, cosmetics, as food additives, and in medical applications [4] [5] [6] because of its antibacterial effects, biodegradability, and biocompatibility [7] [8]. Chitosan is produced industrially via deacetylation of chitin obtained from the shells of crustaceans, such as shrimp and crab, by heat-treating chitin in a concentrated alkaline solution [9]. This alkali treatment does not lead to complete deacetylation but yields chitosan containing about 30\% of GlcNAc at random [3]. In addition, chitosan production from $1 \mathrm{~kg}$ of chitin requires not only $6.3 \mathrm{~kg}$ of $\mathrm{HCl}$ and $1-8 \mathrm{~kg}$ of $\mathrm{NaOH}$ but also nitrogen, $0.5 \mathrm{t}$ of process water, and $0.9 \mathrm{t}$ of cooling water [10]. In contrast, enzymatic deacetylation proceeds under mild conditions and can either completely deacetylate or partially deacetylate chitin at specific sites [11] [12]. Therefore, chitosan production using enzymes is expected to replace alkaline production.

Chitin deacetylase (CDA) is an enzyme that catalyzes the hydrolysis of the acetamido groups of GlcNAc in chitin, producing GlcN and acetic acid [13]. CDA is a member of carbohydrate esterase family 4 (CE4). Members of CE4 share a conserved region called the NodB homology domain or polysaccharide deacetylase domain [14]. CDA was first discovered in the fungus Mucor rouxii [15] [16], and was subsequently found in various fungi and characterized. This enzyme was shown to play important roles in various physiological processes, including cell wall formation, spore formation, and fruiting body growth [17] [18] [19]. In insects, a CDA was discovered in Mamestra configurata [20], and was subsequently identified in the peritrophic membranes of numerous insects. In addition, in beetles, chitin is converted to chitosan when the trachea is extended, which suggests the involvement of CDA in this process [13] [21].

There have been a limited number of reports on CDA genes in crustaceans; specifically, in two varieties of shrimp, red claw shrimp (Cherax quadricarinatus) [22] and black tiger shrimp (Penaeus monodon) [23]. The CDA in P. monodon is reported to be expressed mainly in the gills and play a role in pathogen defense [23]. We attempted, for the first time, to amplify full-length CDA genes from crabs, which has not been often reported, and to determine the structure and phylogenetic relationships among CDAs.

\section{Materials and Methods}

\subsection{Materials}

Red snow crab Chionoecetes japonicas (male, carapace width; $12 \mathrm{~cm}$, weight; $725 \mathrm{~g}$, collected at Ishikawa prefecture Japan on November in 2015) was purchased from Nakagawa Co., Ltd. (Japan). Sample was transported living and then stored at $-80^{\circ} \mathrm{C}$. 


\subsection{Cloning of the Chitin Deacetylase cDNA from $C_{\text {. japonicus }}$}

The sequences of all primers used are presented in Table 1. Total RNA was extracted from the epidermis of the leg muscle of $C$. japonicus using ISOGEN II reagent (Nippon Gene, Tokyo, Japan) according to the manufacturer's instructions. First-strand cDNA was synthesized using $500 \mathrm{ng}$ of total RNA and oligo dT primers with PrimeScript II Reverse Transcriptase (RNase H-free) (Takara Bio, Shiga, Japan) according to the manufacturer's instructions. Degenerate primers were designed for the reverse transcriptase-polymerase chain reaction (RT-PCR) from conserved sequences in insect and crustacean chitin deacetylases. In the first PCR, $C$. japonicus cDNA was used as a template and CDA F-1 and CDA R-1 were used as primers. The PCR conditions were as follows: $95^{\circ} \mathrm{C}$ for $2 \mathrm{~min}$, followed by 30 cycles of $95^{\circ} \mathrm{C}$ for $30 \mathrm{~s}, 55^{\circ} \mathrm{C}$ for $30 \mathrm{~s}$, and $72^{\circ} \mathrm{C}$ for $50 \mathrm{~s}$. The primers used are listed in Table 1, and the primer combinations are shown in Figure 1.

For the 3 ' rapid amplification of cDNA ends (RACE), we designed primers specific to CjCDA (CjCDA 3'-1 and CjCDA 3'-2; Table 1) based on the detected sequences. We amplified cDNA fragments encoding the 3 'region of $C j C D A$ using

Table 1. Primers used for PCR, RACE, and tissue expression.

\begin{tabular}{|c|c|c|c|c|}
\hline Primer name & Sequence & $\begin{array}{l}\text { Number of } \\
\text { bases (bp) }\end{array}$ & $\begin{array}{c}\text { Annealing } \\
\text { temperatures }\left({ }^{\circ} \mathrm{C}\right)\end{array}$ & Uses \\
\hline CDA F-1 & TGYMGNGAYGTNATHCARTGYAC & 23 & 58.4 & Primary PCR \\
\hline CDA F-2 & GGNYTNCARGCNHTNMGNTGYCC & 23 & 63.7 & Primary PCR \\
\hline CDA F-3 & GAYTGYWSNGAYGGNWSNGAYGA & 23 & 61.3 & Primary PCR \\
\hline CDA F-4 & ACNTTYGAYGAYGCNATHAA & 20 & 51.3 & Primary PCR \\
\hline CDA R-1 & CCAYTGDATNACYTGNGTCATNGT & 24 & 58.5 & Primary PCR \\
\hline CDA R-2 & GCNGTDATNGTNSWRTCRTANAARAA & 26 & 57.1 & Primary PCR \\
\hline CDA R-3 & AAYTGNBWRTTNCCNCCNACNCKNA & 25 & 60.8 & Primary PCR \\
\hline CDA R-4 & TAYTTRTGNSWNACRAARAANGT & 23 & 52.4 & Primary PCR \\
\hline$C j C D A 5 '-1$ & GCAGCGGCTTTACTTTCTTTCG & 22 & 58.6 & 5'RACE \\
\hline$C j C D A 5 ' 2$ & TCTGCAGCTCCAGGTCAAAG & 20 & 58.4 & 5 'RACE \\
\hline AAP & GGCCACGCGTCGACTAGTACGGGIIGGGIIGGGIIG & 36 & 76.5 & 5 'RACE \\
\hline AUAP & GGCCACGCGTCGACTAGTAC & 20 & 62.5 & 5 'RACE \\
\hline$C j C D A 3 '-1$ & ACAACCCCAACGGCTGCTC & 19 & 60.4 & $3^{\prime} \mathrm{RACE}$ \\
\hline$C j C D A 3 \div 2$ & GGCTGCTCCATCAAGTCCAC & 20 & 60.4 & 3'RACE \\
\hline 3'RACE & CTGTGAATGCTGCGACTACGAT & 22 & 58.6 & 3'RACE \\
\hline$C j C D A$ Full F & CGATCAGACCGGGAAACAAC & 20 & 58.4 & Full length PCR \\
\hline$C j C D A$ Full $\mathrm{R}$ & CTGGACACAATCATGTATAC & 20 & 52.2 & Full length PCR \\
\hline$\beta$-actin F & ATGTACGTGGCCATCCAGG & 19 & 58.2 & Tissue expression \\
\hline$\beta$-actin $\mathrm{R}$ & CTCGTTGCCGATGGTGATG & 19 & 58.2 & Tissue expression \\
\hline$C j C D A \mathrm{~F}$ & GCCCAACATTACCGACTCTTCG & 22 & 60.4 & Tissue expression \\
\hline$C j C D A \mathrm{R}$ & ATCACCTGCGTCATGGTCACG & 21 & 60.4 & Tissue expression \\
\hline
\end{tabular}




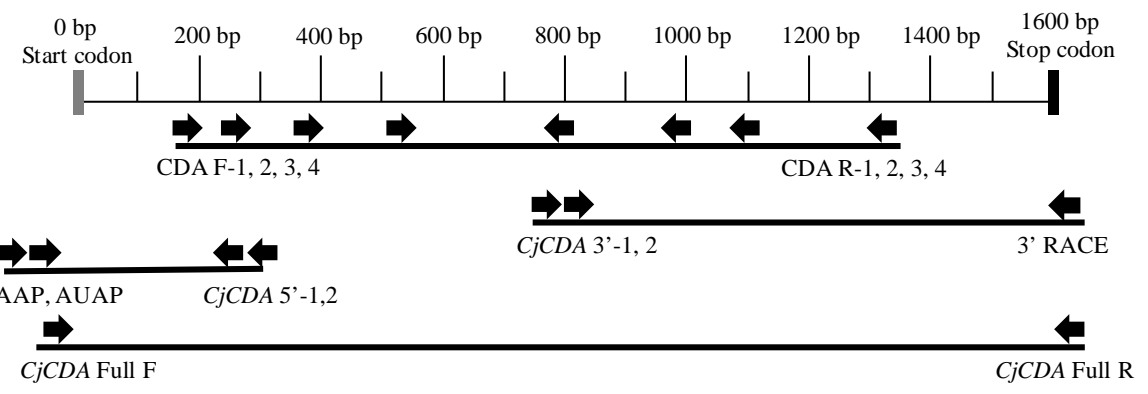

Figure 1. Schematic representation of the cDNA structure of $C j C D A$ and location of the primers. Arrowheads indicate the primers, and lines between the arrowheads indicate the amplified cDNA fragments.

C. japonicus cDNA as the template and the primer pairs $C j C D A 3^{\prime}-1,3^{\prime} \mathrm{RACE}$ and $C j C D A 3^{\prime}-2,3^{\prime}$ RACE. The PCR conditions were as follows: $95^{\circ} \mathrm{C}$ for $2 \mathrm{~min}$, followed by 30 cycles of $95^{\circ} \mathrm{C}$ for $30 \mathrm{~s}, 58^{\circ} \mathrm{C}$ for $30 \mathrm{~s}$, and $72^{\circ} \mathrm{C}$ for $80 \mathrm{~s}$. For the $5^{\prime}$ RACE, specific primers (CjCDA 5'-1 and CjCDA 5'-2; Table 1) were designed based on the nucleotide sequences obtained from the RT-PCR. Then, the cDNA fragments encoding the 5 'regions of $C j C D A$ were amplified by PCR. In the first PCR, the newly synthesized first-strand CDNA was used as a template, and AAP and CjCDA 5'-1 were used as the primers. In the nested PCR, the first PCR products were used as templates and AUAP and CjCDA 5'-2 were used as primers. The PCR conditions were as follows: $95^{\circ} \mathrm{C}$ for $2 \mathrm{~min}$, followed by 30 cycles of $95^{\circ} \mathrm{C}$ for $30 \mathrm{~s}, 56^{\circ} \mathrm{C}$ for $30 \mathrm{~s}$, and $72^{\circ} \mathrm{C}$ for $20 \mathrm{~s}$. The nucleotide sequences of cDNA fragments containing a full-length open reading frame (ORF) were confirmed by PCR using the specific primers $C j C D A$ Full $\mathrm{F}$ and $C j C D A$ Full $\mathrm{R}$ (Table 1) and Platinum Pfx DNA Polymerase (Invitrogen, Carlsbad, CA).

\subsection{Nucleotide Sequence Analysis}

The RT-PCR and $3^{\prime}$ and 5' RACE amplification products as well as the full-length amplification products were subcloned into the pGEM-T Easy Vector (Promega, Madison, WI), according to the manufacturer's instructions. The sequences were determined on an ABI PRISM 3130 genetic analyzer (Applied Biosystems, Foster City, CA) using the Big Dye Terminator v3.1 cycle sequencing kit (Applied Biosystems).

\subsection{Expression Analysis}

Total RNA was prepared from the muscle, epidermis, hepatopancreas, gills, shell, tendon, and intersegmental membrane as described in Section 2.2. Then, first-strand cDNA was amplified from the RNA isolated from each tissue as described above. For tissue-specific expression, we designed primers specific to CjCDA (CjCDA F and CjCDA R; Table 1) based on the detected sequences. Then, $C j C D A$ was amplified using the first-strand cDNA as template and primers $C j C D A \mathrm{~F}$ and $C j C D A$ R (Table 1). The PCR conditions were as follows: $95^{\circ} \mathrm{C}$ for $2 \mathrm{~min}$, followed by 30 cycles of $95^{\circ} \mathrm{C}$ for $30 \mathrm{~s}, 50^{\circ} \mathrm{C}$ for $30 \mathrm{~s}$, and $72^{\circ} \mathrm{C}$ 
for $30 \mathrm{~s}$. To determine the amount of total RNA in each tissue, we amplified $\beta$-actin mRNA using a specific primer pair as a control for normalization (Table $1)$.

\subsection{Phylogenetic Analysis}

To determine the relationship between the CDA isolated from the epidermis of C. japonicus and other CDAs from insects, crustaceans, and mollusks, we constructed a phylogenetic tree based on the sequences of enzyme precursors by the neighbor-joining method using ClustalW2

(http://www.ebi.ac.uk/Tools/msa/clustalw2/). A fungal CDA (GenBank:

XM_007272808.1) was used as an outgroup.

\section{Results and Discussion}

\section{1. cDNA Cloning}

From the epidermis of the leg muscle of red snow crab (Chionoecetes japonicas), we obtained a 2141-bp chitin deacetylase (CDA) gene containing a 1575-bp open reading frame $(\mathrm{ORF})$ that encodes 525 amino acids. The sequence determined for the cDNA encoding the chitin deacetylase $C j C D A$ was registered with the DNA Data Bank of Japan (DDBJ) database (accession no. LC342072). A poly(A) tail specific to eukaryotes was found at the 3 'terminus of $C j C D A$. Comparison of the deduced amino acid sequence of CjCDA (CjCDA) to CDAs in other organisms by BLAST showed the highest similarity (74\%) with gastrolith protein 59 of $C$. quadricarinatus (CqCDA) [22] and the second highest similarity (72\%) with chitin deacetylase1 of P. monodon (PmCDA) [23]. In addition, CjCDAshowed $\sim 60 \%$ similarity was known CDAs in insects. The structural prediction for CjCDA showed an N-terminal signal peptide (amino acids 1 - 18), chitin-binding domain (CBD; amino acids 31 - 90), low-density lipoprotein receptor class A domain (LDL-A; amino acids 103 - 142), and glycoside hydrolase/deacetylase, beta/alpha-barrel (Glyco_hydro/deAcase_b/a-brl; amino acids 145 - 461) (Figure 2). Because amino acids 183 - 293 in the Glyco_hydro/deAcase_b/a-brl are presumed to be the NodB homology domain (NODB_dom) and several characteristic motifs, including TFDD, $\mathrm{H}[\mathrm{S} / \mathrm{T}] \mathrm{xxHP}$, $\mathrm{RxP}[\mathrm{Y} / \mathrm{F}], \mathrm{DxxDW}$, and GxxxFxx [13], are present, CjCDA is considered to be a member of carbohydrate esterases family 4 (CE4). Comparison of CjCDA to the deduced amino acid sequences of $C q C D A, P m C D A$, and known CDAs in insects showed that $\mathrm{CjCDA}$ shares a very similar domain structure with these proteins (Figure 3). The CDAs in insects have been classified into five groups based on their structure (Figure 4) [24]. Groups I and II contain a signal peptide, CBD, LDL-A, and catalytic domain. Groups III and IV contain a signal peptide, CBD, and catalytic domain but no LDL-A. Group V contains only a signal peptide and catalytic domain, and these CDAs are specific to the midgut [24]. Because CjCDA contains a CBD, LDL-A, and catalytic domain, it can be classified into Group I. CqCDA and PmCDA share similar domain structure, and all crustacean 
cgatcagaccgggaaacaac

atgaccaggt tacgct tggcggtggtccttggccttctgggcatcgttgccggccaggaagggggtgaagtgcaacctgaggatctgaca

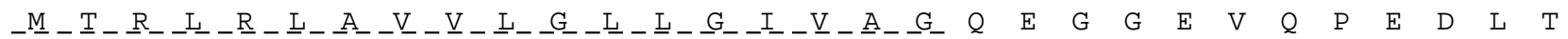
aaggcgctgtgtactgacaagggacccggggagt ggt tcc gtctggcggtgacggattgcagggacgtcatccaatgcaccgaggccggc $\begin{array}{llllllllllllllllllllllllllllllllllll}K & A & L & C & T & D & K & G & P & G & E & W & F & R & L & A & V & T & D & C & R & D & V & I & Q & C & T & E & A & G\end{array}$ ctgcaggcgctgcggtgcccccacggcctggcctttgacc tggagc tgcagacgt gcgact ggagaggcaacg tgaataact gcgacaag $\begin{array}{llllllllllllllllllllllllllllllll}L & Q & A & L & R & C & P & H & G & L & A & F & D & L & E & L & Q & T & C & D & W & R & G & N & V & N & N & C & D & K\end{array}$ aagg tcaaaacgaagaaag taaagccgctgctgcgaaccgtcgagccgctgtgcgaggagaact tcctggcttgcggcgatggcgtgtgc $\begin{array}{lllllllllllllllllllllllllllllllll}K & V & K & T & K & K & V & K & P & L & L & R & T & V & E & P & L & C & E & E & N & F & L & A & C & G & D & G & V & C\end{array}$ atggaccagcagctgt tctgtgacagcaagccagact gcgcggacggct ctgatgaaaact cctgcgacgtggacaacgaccccaacagg $\begin{array}{llllllllllllllllllllllllllllllllll}M & D & Q & Q & L & F & C & D & S & K & P & D & C & A & D & G & S & D & E & N & S & C & D & V & D & N & D & P & N & R\end{array}$ gcgccactctgcaaccagaaggact gcaacc tgc cagact gctact gct tccacgaccccagcgagatcccaaataact acaatatcaac

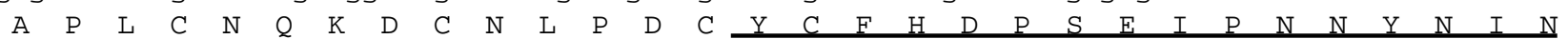
gatgtgccccaaatgattacgatcacct tcgatgacgcaatcaacaacaacaacaatgacctctatcagctgatat tcaacggccgctac $\begin{array}{lllllllllllllllllllllllllllllllllllll}D & V & P & O & M & I & T & I & T & F & D & D & A & I & N & N & N & N & N & D & L & Y & 0 & L & I & F & N & G & R & Y\end{array}$ aaccccaacggct gctccatcaagt ccacct tct tcgtgtctcataagtacaccaact acacctccgtgcaggagatgcatcgccagggt

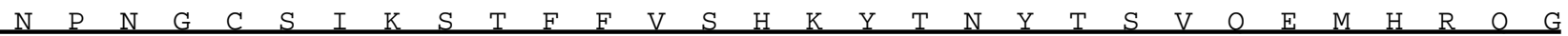
cacgagatcgccgtccactccatcagccacaacaccagcgaggatt tct ggacggatgcgtcgcaggact tgtgggagcgcgagatggct

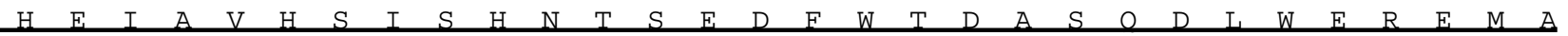
ggcgcgcgcgtcatcgtggagcgat tcgccaacattaccgactcttcggtgatcggcatccgcgcaccctacctgcgtgtgggtggcaac

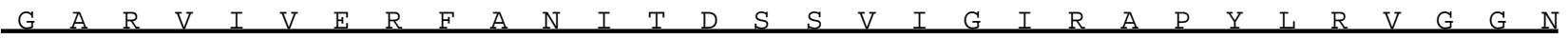
aaccagt tcactatgatggagaagaaccagt ttc tgtacgactccaccatcaccgcgcccctgtcgcccactcccctgtggccctacacc

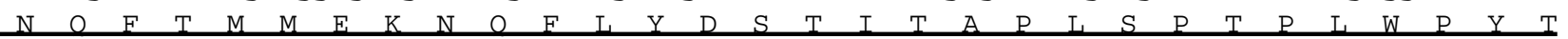
ctctactaccgcatgccccacgtgtgccacggcaacgcccagaagt gtcccacgcggtccttcgcggtgtgggagatggtgatgaacgag

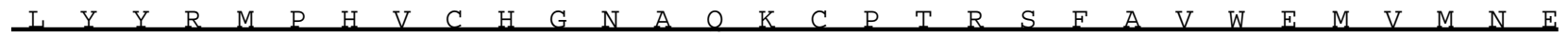
atggaccgtcgtgaggaacccgcgt tggaggcggagctgccoggctgtgccatggtggactcctgct tctccagcaagcccaccgctgat

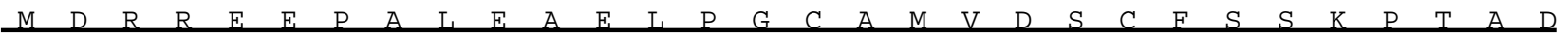
caat tct tcaact tcctcaacaacaact tcgaccgtcactact tgacaaaccgcgcccetcttggacttttct tccactccgccttcctg

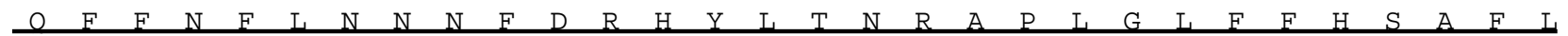
aaaaacgaccccgagatcctggacgcct tcctct tctggctggacgagactctcgccacttacaaggacgtgtact tcgtgaccatgacg $\begin{array}{llllllllllllllllllllllllllll}K & N & D & P & E & I & L & D & A & F & L & F & W & L & D & E & T & L & A & T & Y & K & D & V & Y & F & V & T\end{array}$ cagg tgatccagtggatgcaggaccccaagcccaacaaccagctcaacgcctacgaggcctggagggataaatgcgaggtgaacagccaa

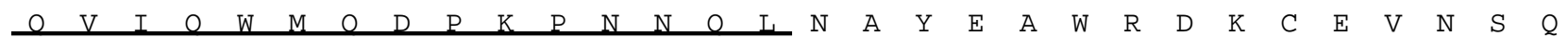
ccctactgcgtgggcggcagcgactgcgagc taaacaccgaggagctgcccggcgagacce tgc gcctcaacacctgcatgcgct gcc

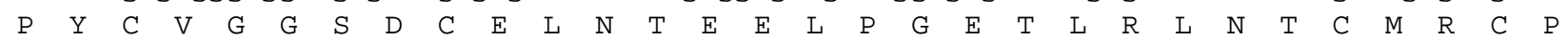
aacaagtaccctggctacttgatcccctgggcgagggat ttt tctaagacaactaacacactgaaaaactcctcgttgccacctgctcc $\begin{array}{llllllllllllllllllllll}N & K & Y & P & W & L & L & D & P & L & G & E & G & F & F & *\end{array}$ cccaggg tgatccgggagacccct cccagccct cccccctcgccoggggcgcagcacctacacctgtaaatactgttttataattgtg tatacatgat tgtgtccagacgagcgtggccgcg ccctcacct cactcatcatcc ccc gccocgcccogccctcccgagccccgcgttt taccttccctcactttccatgacaggtcaaggtgggt cacacgcactcg taagaggtcatcgggtcacatcccctccctacattcctca tcccaat tt ccctctgtcccagcgtgacctgttgcggccctcttggtatt attagagct ggaggagccctcccccctccacacggcc ggccccaccccogcacgcgcgaggttt tat tagctg tgatgatcg tactgattattactt tcattggttttattactttccatatt $t$ gcgtttcatgttacccaataaaacattattccttaaaaaaaaaaaaaaa

Figure 2. Full-length sequence and deduced amino acid sequence of $C j C D A$. Signal peptides are indicated by a dotted line. The chitin-binding domain is highlighted in pale gray, and the low-density lipoprotein receptor class A domain is highlighted in dark gray. The glycoside hydrolase/deacetylase, beta/alpha-barrel including the NodB homology domain is underlined with a solid line.

CDAs that have been discovered to date appear to belong to Group I.

\subsection{Tissue Expression}

Tissue expression analysis of $C j C D A$ in $C$. japonicus by RT-PCR using the $\beta$-actin gene as a control revealed that $C j C D A$ is expressed only in the epidermis of muscle (Figure 5), and no expression was observed in gills, muscle, or other examined tissues. Previous studies revealed that $P m C D A$ in $P$. monodon is mainly expressed in the gills and functions in the immune response to the pathogen that causes white spot disease [23] and the CDA in the fruit fly Drosophila 

MARVRCGSSLALLGIVLPSGSRGRQ - - FQTRPRMERTFKRELCKDKGAGEWFRLSLG - - - DCRDVIQCTD - - - - - AGLQ - - MALKQGALFILAICACTVFAQQQAEETAPKKEDSFE VE LCKDKDAGEWFRLVAGEGDNCRDVIQCTS - - - - - - SGLQ -MARHAFLCLGVLLVGSLNCSTSRVKRQDDDGAGDEPNAфQ LCDGRPADEYFRLTTEG - -DCRDVVRCDQGLENSVTRLA

ALRCPHGLAFD LELQTCDWRGNVNNCDKKVKTKKVKPLLRTVEPLCEENFLACGDGVCMDQQLFCDSKPDCADGSDENSC ALRCP HGLAFD LELQTCDWKANVKNCADKQKIKKAKPLFNTEEPLCQENFLACGDSTCMDRTLFCDGKPDCSDGSDENAC ALRCPHGLAFN LEQQTCDWKANVKNCDRKEKTKVVKPLFNTVEPLCQENQLACGDGTCLDRQVFCDGKEDCTDGSDETAC AIRCPAGLYFDIDKQTCDWKDSVKNCKL KNKERKVKPLLITDEPLCPDGSLACGDGNCI ERGLFCNGEKDC SDGSDENTC SVRCP GGLAFDIDRQTCDWKTNVKNCDQIEKPRKVLPILKTDEPICPEGKLACGSGDCI EKELFCNGKPDCKDESDENAC Glyco hydro/deAcase b/a-brl DVWNDPNRAPLCNQKDCNLPDCYCFHDPSEIPNNYNINDVPQMITI FDDAINNNNNDL YQLIFNG-RYNPNGCSIKSTF DINTDPNSAPP CNPDECRLPDCFCYNNPNEIPHKMQPSSVPQMIMI FDDAINNNNMDL YQQIFDN-RFNPNQCSIKATF DVKNDPNSAPI CNTEDCRLPDCYCYNDPSEMPHNM KPSEVPQMVTI IFDDAIN INNMDL YELIFKQ-RFNPNGCSIKSTF DIDNDPNRAPPCDPAVCVLPDCFCSEDGTTIPGDL PSKDVPQMITI FDDAINNNNIELYKEIFNGKRKNPNGCDIKATF TVELDPNRAPD CDPNQCVLPDCFCSADGTRIPGGI EPNQVPQMVTI FNGAVNVDNIDL YEQIFNGNRHNP NGCQIKGTF

FVSHKYTNYTSVQEMHRQGHEIAVHSISHNTSEDFWTDASQDLWEREMAGARVIVERFANITDSSVIGIRAPYLRVG GNN FVSHKYTNYSAVQEMHR LGHEIA I HSISHNDSESFWSSASYDEWEREMAGARV IAERFANISDNS IIGLRAPYLRVG GNN FVSHKYNNYTATQEMHR LGHEIAVHSITHANNETFWSHASEDEYEREMGGARV IIERFANITDQS I IGMRN PFLRVG GNS FVSHKYTNYSAVQEMHRKGHEIAVHSITHNDDERFWSNATVDDWAKEMAGMRI IAEKFANLTDNSVVGVRAPYLRVGGNN FVSHKYTNYAAVQELHRKGHEISVESITHKDDPQYWTSGSYDDWLAEMAGARL IIERYANITDSS IIGVRAPYLRVG GNK

QFTMMEKNQFLYDS ITAPLSPTPLWPYT YYRMPHVCHGNAQKCPTRSFAVWEMVMNEMDRREEPALEAELPGCAMVDS QFKMMETNTFLYDS ITASLQNPPLWPYT_YYRMPHSCHGNSQNCPTRSFAVWEMVMNEMDRREEPTIQEDLPGCAMVDS QFRMMEKNTFLYDS ITAPLSSMPLWPYT_YYRMP HPCHGN LQNCPTRSFAVWEMVMNEMDRREEPTYEDGLPGCHMVDS QFTMMEEQAFLYDS IT APLSNPPLWPYT MYFRMP HRCHGN LQSCPTRSHAVWEMVLNELDRREDPTNDEY LPGCAMVDS QFEMMGDQYEVYDA $\$$ ITAPLGRVPIWPYT_YFRMPHKCNGNAHNCPSKSHPVWEMVMNELDRRDDPTFDESLPGCHVVDS

CFSSKPTADQFFNFLNNNFDRHYLTNRAP LGLFFHSAFLKNDPEILDAFLFWLDETLATYKDVYFVTMTQVIQWMQDPKP CFSSKPTSDQFYQFLTNNFERHYHTNRAPFGLFFHSAFLKNNPEILDALFYWLDETLQT NDDVYFVTMTQVIQWIQDPQP CFATKPEPEQFYNFLQNNFNRHYKSNRAP FGLFFHSAFLKN NPDILDTFLYWLDETLKNQKDVYFVTMTQVIQWMQDPRP CSN - I LTGDQFYNFLNHNFDRHYEENRAP LGLYFHAAWLKNNPEFLDAFLYWVDEILAN HNDVYFVTMTQV IQWIQNPRT CSN - IQSGEQL GRLLRH NFNRHYTTNRAP LGFHFHASWLKSKKEYRDELIKFI EEMLE- KNDVYFTSLIQV IQWMQNPTE

NNQLNIAYEAWR - DKCEVNSQPYCVGGSDCELNTEE LPGETLRLNTCMRCPNKYPWLLDP LGEGFF - - VNQLIKNYEPWK - EKCNPTGPPFCYGGTNCELSTDELPGETIRLNTCMRCPNKYPWLKDP LGEGYF - - VGQLNINYEAWK - EKCVVDGPPFCYGGNNCELDTDELPGQTL HLSTCMRCPNNYPWTRDP LGEGFF - - ITESIKNFEPWR - EKCVVEGNPHCWVPHSCKLTSKEVPGETI NLQTCVRCPNNYPWVNDPTGDGFF - - LSSLRDFQEWKQDKCDVKGQPFCSLPNACPLTTRELPGETLRLFTCMECPNNYPWILDPQGEGYNVKK

Figure 3. Comparison of the deduced amino acid sequence of $C j C D A$ to the deduced amino acid sequences of CDAs from crustaceans and insects (CqCDA: Cherax quadricarinatus, ALC79575.1; PmCDA: Penaeus monodon, ALO20448.1; TcCDA: Tribolium castaneum, ABU25223.1; BmCDA: Bombyx mori, ADO24153.1). CE4 domain motifs are enclosed in boxes.

melanogaster is involved in the control of trachea extension [21]. In addition, the CDAs of D. melanogaster and a species of locust, Locusta migratoria, are expressed in the cuticle [21] [25]. Because inhibition of CDA expression in a species of beetle (Tribolium castaneum) prevented ecdysis, CDA is thought to play an important role in ecdysis [24]. When arthropods molt, the epidermis separates from the cuticle and a new cuticle is secreted on the surface of the epidermis. Thus, we hypothesize that $\mathrm{CjCDA}$ has some function during $C$. japonicus molting.

\subsection{Phylogenetic Analysis}

As a result of phylogenetic analysis based on the deduced amino acid sequences of CDAs from various arthropods, including insects and crustaceans, as well as 
mollusks and the fungus Colletotrichum gloeosporioides, which was used as an outgroup, CDAs in arthropods were shown to belong in Groups I-V, as reported previously [24]. However, the CDAs from mollusks were not in Groups I-V. All CDAs from crustaceans, including CjCDA, belonged to Group I (Figure 6).

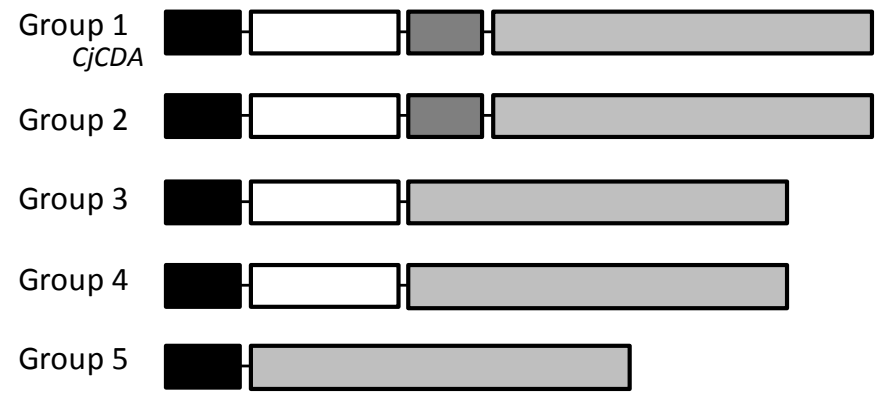

Figure 4. Domain structure of CDAs. Black boxes indicate signal peptides, white boxes indicate chitin-binding domains, dark gray boxes indicate low-density lipoprotein receptor class A domains, and pale gray boxes indicate the catalytic domains of chitin deacetylase-like proteins.

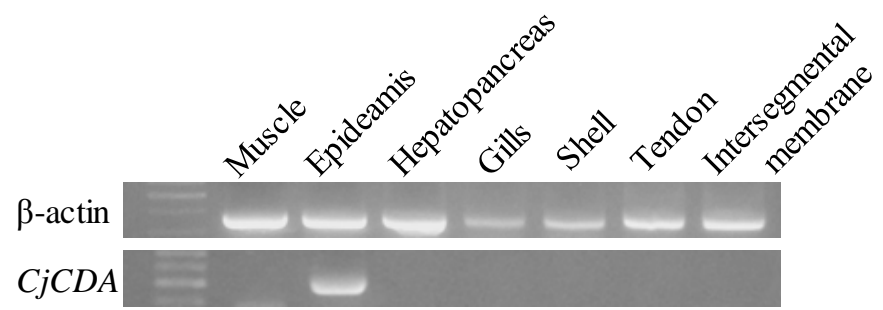

Figure 5. Agarose gel electrophoresis showing the tissue expression pattern of $C j C D A$.

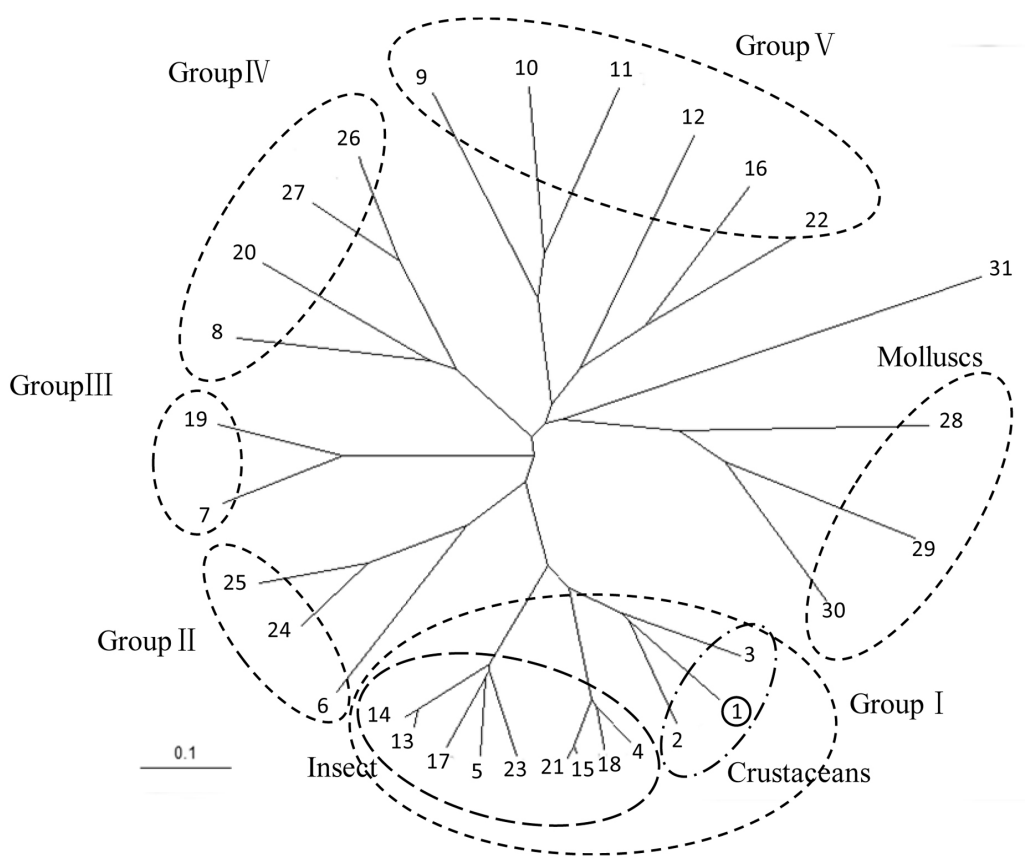




\begin{tabular}{|c|c|c|c|c|c|}
\hline Number & Species & $\begin{array}{c}\text { GB accession } \\
\text { number }\end{array}$ & Number & Species & $\begin{array}{c}\text { GB accession } \\
\text { number }\end{array}$ \\
\hline 1 & Chionoecetes japonicus & LC342072 & 17 & Nilaparvata lugens CDA1 & AJQ20732.1 \\
\hline 2 & Cherax quadricarinatus & ALC79575.1 & 18 & Nilaparvata lugens CDA2 & AJQ20733.1 \\
\hline 3 & Penaeus monodon & ALO20448.1 & 19 & Nilaparvata lugens CDA3 & AJQ20734.1 \\
\hline 4 & Tribolium castaneum CDA1 & ABU25223.1 & 20 & Nilaparvata lugens CDA4 & AJQ20735.1 \\
\hline 5 & Tribolium castaneum CDA2 & NP_001096047.1 & 21 & Mamestra brassicae CDA1 & AEI30868.1 \\
\hline 6 & Tribolium castaneum CDA3 & ABW74145.1 & 22 & Mamestra brassicae CDA2 & AEI30869.1 \\
\hline 7 & Tribolium castaneum CDA4 & ABW74146.1 & 23 & Lucilia cuprina & ABI95429.1 \\
\hline 8 & Tribolium castaneum CDA5 & NP_001103739.1 & 24 & Anopheles gambiae & XP_317336.3 \\
\hline 9 & Tribolium castaneum CDA6 & ABW74149.1 & 25 & Drosophila melanogaster CDA3 & NP_609806.1 \\
\hline 10 & Tribolium castaneum CDA7 & ABW74150.1 & 26 & Drosophila melanogaster CDA5A & NP_722589.1 \\
\hline 11 & Tribolium castaneum CDA8 & ABW74151.1 & 27 & Drosophila melanogaster CDA5B & NP_722590.2 \\
\hline 12 & Tribolium castaneum CDA9 & ABW74152.1 & 28 & Hyriopsis cumingii & AFO53262.1 \\
\hline 13 & Bombyx mori CDA1 & ADO24153.1 & 29 & Mytilus coruscus & AKS48153.1 \\
\hline 14 & Bombyx mori CDA2 & ADO24154.1 & 30 & Crassostrea virginica & XP_022333470.1 \\
\hline 15 & Helicoverpa armigera CDA1 & ADB43610.1 & 31 & Colletotrichum gloeosporioides & XM_007272808.1 \\
\hline 16 & Helicoverpa armigera CDA5b & ADB43612.1 & & & \\
\hline
\end{tabular}

Figure 6. Phylogenetic analysis of the deduced amino acid sequences of CDAs using ClustalW.

There are no reports of CDAs from crustaceans belonging to any Group other than Group I. However, because some species have multiple CDA isozymes, like $T$. castaneum, there is a possibility that $C$. japonicus may contain multiple isozymes with different structures, like T. castaneum.

\section{Conclusion}

From the epidermis of the red snow crab, we obtained a full-length CDA gene, CjCDA, which contained a 1575-bp ORF encoding a 525-amino acid protein. $\mathrm{CjCDA}$ had a Group I domain structure, as it contained a signal peptide, CBD, LDL-A, and catalytic domain. Because CjCDA was expressed only in the epidermis, we hypothesize that it is involved in ecdysis. This study is the first report of the cloning of a full-length CDA gene from a crab.

\section{References}

[1] Islam, S., Rahman Bhuiyan, M.A. and Islam, M.N. (2017) Chitin and Chitosan: Structure, Properties and Applications in Biomedical Engineering. Journal of Polymers and the Environment, 25, 854-866. https://doi.org/10.1007/s10924-016-0865-5

[2] El-Nesr, E.M., Raafat, A.I., Nasef, S.M., Soliman, E.A. and El-Sayed, A.H. (2013) Chitin and Chitosan Extracted from Irradiated and non-Irradiated Shrimp Wastes (Comparative Analysis Study). Arab Journal of Nuclear Science and Applications, 46, 53-66.

[3] Majeti, N.V. and Kumar, R. (2000) A Review of Chitin and Chitosan Applications. Reactive \& Functional Polymers, 46, 1-27. https://doi.org/10.1016/S1381-5148(00)00038-9

[4] Kanimozhi, S., Ramya, D. and Menaga, G.M.R. (2014) Production and Optimiza- 
tion of Chitosan from Aspergillus niger by Solid State and Submerged Fermentation and Evaluation of its Antibacterial and Antioxidant Activity. Drug Invention Today, 6, 141-148.

[5] Abdou, E.S., Elkholy, S.S., Elsabee, M.Z. and Mohamed, E. (2008) Improved Antimicrobial Activity of Polypropylene and Cotton Nonwoven Fabrics by Surface Treatment and Modification with Chitosan. Journal of Applied Polymer Science, 108, 2290-2296. https://doi.org/10.1002/app.25937

[6] Dutta, P.K., Tripathi, S., Mehrotra, G.K. and Dutta, J. (2009) Perspectives for Chitosan Based Antimicrobial Films in Food Applications. Food Chemistry, 114, 1173-1182. https://doi.org/10.1016/j.foodchem.2008.11.047

[7] Zheng, L.Y. and Zhu, J.F. (2003) Study on Antimicrobial Activity of Chitosan with Different Molecular Weights. Carbohydrate Polymers, 54, 527-530. https://doi.org/10.1016/j.carbpol.2003.07.009

[8] Nishimura, S., Kohgo, O., Kurita, K. and Kuzuhara, H. (1991) Chemospecific Manipulations of a Rigid Polysaccharide: Syntheses of Novel Chitosan Derivatives with Excellent Solubility in Common Organic Solvents by Regioselective Chemical Modifications. Macromolecules, 24, 4745-4748. https://doi.org/10.1021/ma00017a003

[9] Aam, B.B., Heggset, E.B., Norberg, A.L., Sørlie, M., Varum, K.M. and Eijsink, V.G.H. (2010) Production of Chitooligosaccharides and Their Potential Applications in Medicine. Marine Drugs, 8, 1482-1517. https://doi.org/10.3390/md8051482

[10] Kumar, M.N.V.R. (1999) Chitin and Chitosan Fibres: A Review. Bulletin of Materials Science, 22, 905-915. https://doi.org/10.1007/BF02745552

[11] Shrestha, B., Blondeau, K., Stevens, W.F. and Hegarat, F.L. (2004) Expression of Chitin Deacetylase from Colletotrichum lindemuthianum in Pichia pastoris. Purification and Characterization. Protein Expression and Purification, 38, 196-204. https://doi.org/10.1016/j.pep.2004.08.012

[12] Naqvi, S., Cord-Landwehr, S., Singh, R., Bernard, F., Kolkenbrock, S., Gueddari, N.E.E. and Moerschbacher, B.M. (2016) A Recombinant Fungal Chitin Deacetylase Produces Fully Defined Chitosan Oligomers with Novel Patterns of Acetylation. American Society for Microbiology, 82, 6645-6655. https://doi.org/10.1128/AEM.01961-16

[13] Zhao, Y., Park, R. and Muzzarelli, R.A.A. (2010) Chitin Deacetylases: Properties and Applications. Marine Drugs, 8, 24-46. https://doi.org/10.3390/md8010024

[14] John, M., Röhrig, H., Schmidt, J., Wieneke, U. and Schell, J. (1993) Rhizobium NodB Protein Involved in Nodulation Signal Synthesis Is a Chitooligosaccharide Deacetylase. Biochemistry, 90, 625-629. https://doi.org/10.1073/pnas.90.2.625

[15] Davis, L.L. and Bartnicki-Garcia, S. (1984) Chitosan Synthesis by the Tandem Action of Chitin Synthetase and Chitin Deacetylase from Mucor rouxii. Biochemistry, 23, 1065-1073. https://doi.org/10.1021/bi00301a005

[16] Araki, Y. and Ito, E. (1974) A Pathway of Chitosan Formation in Mucor rouxii: Enzymatic Deacetylation of Chitin. Biochemicaland Biophysical Research Communications, 56, 669-675. https://doi.org/10.1016/0006-291X(74)90657-3

[17] Christodoulidou, A., Briza, P., Ellinger, A. and Bouriotis, V. (1999) Yeast Ascospore Wall Assembly Requires Two Chitin Deacetylase Isozymes. Federation of European Biochemical Societies, 460, 275-279. https://doi.org/10.1016/S0014-5793(99)01334-4

[18] Baker, L.G., Specht, C.A., Donlin, M.J. and Lodge, J.K. (2007) Chitosan, the Deacetylated Form of Chitin, Is Necessary for Cell Wall Integrity in Cryptococcus neoformans. Eukaryotic Cell, 6, 855-867. https://doi.org/10.1128/EC.00399-06 
[19] Yamada, M., Kurano, M., Inatomi, S., Taguchi, G., Okazaki, M. and Shimosaka, M. (2008) Isolation and Characterization of a Gene Coding for Chitin Deacetylase Specifically Expressed during Fruiting Body Development in the Basidiomycete Flammulina velutipes and Its Expression in the Yeast Pichia pastoris. Federation of European Microbiological Societies, 289, 130-137.

https://doi.org/10.1111/j.1574-6968.2008.01361.x

[20] Toprak, U., Baldwin, D., Erlandson, M., Gillott, C., Hou, X., Coutu, C. and Hegedus, D.D. (2008) A Chitin Deacetylase and Putative Insect Intestinal Lipases Are Components of the Mamestra configurata (Lepidoptera: Noctuidae) Peritrophic Matrix. Insect Molecular Biology, 17, 573-585.

https://doi.org/10.1111/j.1365-2583.2008.00829.x

[21] Luschnig, S., Bätz, T., Armbruster, K. and Krasnow, M.A. (2006) serpentine and vermiform Encode Matrix Proteins with Chitin Binding and Deacetylation Domains That Limit Tracheal Tube Length in Drosophila. Current Biology, 16, 186-194. https://doi.org/10.1016/j.cub.2005.11.072

[22] Yudkovski, Y., Glazer, L., Shechter, A., Reinhardt, R., Chalifa-Caspi, V., Sagi, A. and Tom, M. (2010) Multi-Transcript Expression Patterns in the Gastrolith Disk and the Hypodermis of the Crayfish Cherax quadricarinatus at Premolt. Comparative Biochemistry and Physiology Part D, 5, 171-177. https://doi.org/10.1016/j.cbd.2010.03.010

[23] Sarmiento, K.P., Panes, V.A. and Santos, M.D. (2016) Molecular Cloning and Expression of Chitin Deacetylase 1 Gene from the Gills of Penaeus monodon (Black Tiger Shrimp). Fish \& Shellfish Immunology, 55, 484-489. https://doi.org/10.1016/j.fsi.2016.06.025

[24] Dixit, R., Arakane, Y., Specht, C.A., Richard, C., Kramer, K.J., Beeman, R.W. and Muthukrishnan, S. (2008) Domain Organization and Phylogenetic Analysis of Proteins from the Chitin Deacetylase Gene Family of Tribolium castaneum and Three Other Species of Insects. Insect Biochemistry and Molecular Biology, 38, 440-451. https://doi.org/10.1016/j.ibmb.2007.12.002

[25] Yu, R., Liu, W., Li, D., Zhao, X., Ding, G., Zhang, M., Ma, E., Zhu, K.Y., Li, S., Moussian, B. and Zhang, J. (2016) Helicoidal Organization of Chitin in the Cuticle of the Migratory Locust Requires the Function of the Chitin Deacetylase2 Enzyme (LmCDA2). Journal of Biological Chemistry, 291, 24352-24363.

https://doi.org/10.1074/jbc.M116.720581 